\title{
A novel hybrid TOPSIS-PSI approach for material selection in marine applications
}

\author{
SUKRITI YADAV ${ }^{1, *}$, VIMAL KUMAR PATHAK ${ }^{2}$ and SWATI GANGWAR ${ }^{1}$ \\ ${ }^{1}$ Department of Mechanical Engineering, Madan Mohan Malaviya University of Technology, Gorakhpur, India \\ ${ }^{2}$ Department of Mechanical Engineering, Manipal University Jaipur, Jaipur, Rajasthan, India \\ e-mail: sukritiyadav09@gmail.com; vimalpthk@gmail.com; vimalkumar.pathak@jaipur.manipal.edu; \\ gangwar.swati@gmail.com
}

MS received 26 February 2018; revised 10 September 2018; accepted 11 September 2018; published online 9 February 2019

\begin{abstract}
Selection of material in engineering design process is a difficult and elusive task due to enormous number of dissimilar materials availability. For effective selection of materials, the designers have to take into account a number of definite qualitative and quantitative criteria. In the same context, this paper proposes a hybrid TOPSIS-PSI approach for effective material selection in marine applications. In this paper, the selection index value has been calculated by using logical combination of PSI and TOPSIS algorithm and these values have been ranked in ascending or descending order. The highest preference selection index value has been taken as the best alternative for the marine application. To prove the effectiveness of the proposed hybrid TOPSIS-PSI algorithm, two practical examples are considered and the result shows that the proposed procedure provides satisfactory results when compared with past literature. Furthermore, hybrid procedure is performed for selection of best wt.\% combination among hybrid aluminum nanocomposites for marine applications based on its physical, mechanical and corrosive behavior. The result reveals that 9 wt.\% and 6 wt.\% reinforced hybrid aluminum nanocomposites have optimum combination of all physical, mechanical and corrosion properties, respectively according to hybrid TOPSIS-PSI approach.
\end{abstract}

Keywords. PSI optimization; TOPSIS method; hybrid method; material selection.

\section{Introduction}

An ever-increasing progress in the technological innovations leads to development of material having its own characteristics, applications, limitations and advantages. Materials are responsible for the effective functionality, structure and strength of the product that plays an important role in the material design and manufacturing process. In recent times, the newly developed materials are replacing the traditionally used materials to fulfil the demands of producing low cost, low weight and better performance materials $[1,2]$. In the same perspective, novel materials with high strength and low-density needs to be developed, which reduces the weight of transportation vehicles (automobiles, aircraft, marine, etc.), as well as increasing engine operating temperatures that results to enhance the fuel efficiency [3]. However, selection of appropriate material for specific application is a critical task requiring a good amount of knowledge, time and expertise [4]. Moreover, faulty choice of material selection leads to reduction in product performance and may also result in early product failure, affecting the reputation of concerned organization

*For correspondence
[5]. Therefore, it becomes essential for design personnel to identify and select optimum material for specific applications and improved performance.

In the past, a great deal of work has been conducted on aluminum metal alloy composites because they are widely used in aircrafts, defense, automobile and marine areas due to their attractive properties such as good strength, light in weight, good corrosion resistance, improved hardness and wear resistance, etc. [6]. By combining two or more materials one can meet the performance requirements of today's advanced technology. In recent years, ceramics are widely used as reinforcement materials in the fabrication of composites, these includes Alumina, Silicon Carbide, Zirconia, etc. and these reinforcements are embedded in the matrix. These matrix phase materials are generally continuous in nature such as Aluminium, Zinc, Titanium, etc. whereas the reinforcements are the dispersed phase in the form of particulates, fibers, flakes [7]. These metal alloy composites exhibit superior properties over conventional monolithic alloys such as high wear resistance, high strength to weight ratio, low thermal expansion at much lower cost [8].

One of the main hurdles in the use of metal alloy composites in marine applications is the effect of environment and chemicals on the composites, which requires corrosion 
resistant materials. It destroys the metal surface by converting them into oxides or other corrosion products and under serious consideration because it leads to loss of material, loss of performance, loss of properties of material such as mechanical, electrical and chemical property. Many efforts have been taken to enhance the service life of the metal alloy composites and for the development of preservative surface coatings and treatments, corrosion inhibitors, etc. [9]. Corrosion phenomenon is distinctly more important in aluminum alloy and its composites where a natural protective oxide film on the surface of material prevent it from corroding. The addition of ceramic particulate could lead to localized breakdown of protective films and it contributes to the corrosion of the aluminumbased composites [10].

For improved product output and functionality, design engineers have to keep in mind different significant criteria for selecting the right material. During material selection, some important criteria that are generally considered include mechanical characteristics, physical characteristics, corrosive characteristics, market scenario, material cost and safety [11-15]. Each material has different performance for different criterion and sometimes it is of conflicting nature [16]. It is very rare that any individual material is meeting and satisfying all criteria. These types of problems selecting contrasting and conflicting criteria can be treated as a complex multi-criteria decision making (MCDM) problem. To solve such kind of complex problems, a systematic, efficient and logical methodology is required that can help organizations in taking material selection decision easily.

In the past, lot of mathematical approaches have been developed and used in the literature for material selection based on different criteria. The most common being the graphical or the ranking method of material selection $[17,18]$. A selection method based on a number of questionnaires have been proposed by Edwards [5] for selecting optimal design solutions. Maniya and Bhatt had presented a novel material selection method known as preference selection index (PSI) to meet design engineers requirement [19]. One similar study was performed by Shanian and Savadogo which proposed a new effective material selection method known as ELECTRE [20]. The main advantage of this method is that there is no demand for normalization of scores. On the other hand, weight must be defined separately as the weighting techniques is not part of this method. Karande et al in their study applied desirability function along with utility concept for effective material selection [21]. One similar study by Zhou et al [22] presented an integrated method for material selection using artificial neural network (ANN) and genetic algorithm (GA) and solve the multi criteria problem for sustainable material selection. Chan and Tong [23] applied grey relational analysis approach (GRA) for multi-criteria material selection and life cycle analysis. Furthermore, a new method for material selection is applied using fuzzy analytic hierarchy process (AHP) [24]. Some researchers used a complex proportional assessment method for effective performance in the different design application as well as for cutting tool material selection $[25,26]$.

The other common techniques that have been available to solve multi criterion decision making (MCDM) problems are MOORA method (multi objective optimization by ratio analysis), TOPSIS method (technique for order preferences by similarity to ideal solution), DEA (data envelopment analysis) method, AHP (Analytic hierarchy process), VIKOR [27-30]. The VIKOR method uses linear means for normalizing and it has more precision for final ranking. The best alternative is preferred by maximizing utility group and minimizing regret group. VIKOR method calculates ratio of positive and negative ideal solution; thus, VIKOR method proposes a compromise solution with an advantage rate. The PSI (Preference selection index) method is very simple (involves less calculation) has significance when there have been struggle in deciding the relative importance among considered variables [19, 31]. In this method, it is not compulsory to assign a relative significance to the variables and the overall preference value is obtained using statistical concept. Moreover, PSI method is helpful in determining optimal criterion value with less numerical calculations. The TOPSIS method is more proficient in dealing with the physical attributes and the number of available alternatives that need to be evaluated [32, 33]. However, TOPSIS method requires an effective methodology to evaluate the relative significance among different criteria with reference to the given objective and PSI method provides such an efficient methodology. In classical MCDM methods, along with classical TOPSIS and PSI method the weights of the criteria and performance ratings of alternatives are known precisely. However, in most of the conditions, these weights data are insufficient to model realistic situations as the human judgements including preferences are often vague and cannot estimate with an exact numerical value.

Although, lot of distinctive techniques have been used till date for effective material selection, but most of the methods still lacks the ability to explore among the interrelationship between the different criteria. Therefore, to bridge this gap and take the advantage of commonly used TOPSIS method and largely ignored PSI method, a hybrid TOPSIS-PSI method is proposed for selection of suitable material from a set of available alternatives. In addition, the criteria weighing is performed using new weighing method by the combination of entropy and PSI method. The weighing method will be the combination of objective and subjective weights. The proposed hybrid approach can be applied in different studies for preserving the interrelationships among criteria. However, some of the strengths of other methods that are not incorporated in the proposed hybrid TOPSIS-PSI method are use of linear means for normalizing (VIKOR), no demand for weighing and normalization of scores (ELECTRE), user friendly and easier to understand (EXPROM2) and stochastic dominance 
(PROMETHEE). This paper presents the optimization of the hybrid aluminium nanocomposites for marine conditions on the basis of its physical, mechanical and corrosive behavior for selection of the best combination of wt.\% of hybrid reinforcements.

\section{Proposed hybrid TOPSIS-PSI method}

As the material selection for any engineering design is a MCDM problem which considers different conflicting criteria for suitable material selection. The set of iterative steps for the proposed hybrid MCDM method are as follows.

Step 1: The first step of the proposed method is the determination of objective and identifying the appropriate criteria. For any particular study, after determining relevant attributes for the given engineering domain problem, sorting of the available materials is performed based on attributes satisfaction. Based on the experimental trials, a qualitative value is assigned to each of the available criteria as a limiting value for its acceptance for the considered application. The available materials meeting these criteria are shortlisted.

Step 2: The second step is creation of decision matrix based on all available information of attributes. The decision matrix has been created by the performance values of various alternatives relating to distinct attributes of the problem. If the number of attributes has been assigned in column, which is taken as $\mathrm{N}$ and number of alternatives has been assigned in rows, which is taken as $\mathrm{M}$, then $\mathrm{M} \times \mathrm{N}$ decision matrix can be represented as;

$$
\mathrm{X}_{\mathrm{ij}}=\begin{array}{ccc}
\mathrm{X}_{11} & \mathrm{X}_{12} \ldots & \mathrm{X}_{1 \mathrm{~N}} \\
\mathrm{X}_{21} & \mathrm{X}_{22} \ldots & \mathrm{X}_{2 N} \\
\vdots & \vdots & \vdots \\
\mathrm{X}_{\mathrm{M} 1} & \mathrm{X}_{\mathrm{M} 2} \ldots & \mathrm{X}_{\mathrm{MN}}
\end{array}
$$

Therefore, an element $X_{i j}$ of the decision matrix actually means the value of $\mathrm{i}^{\text {th }}$ attribute and $\mathrm{j}^{\text {th }}$ alternative.

Step 3: In this step, the above created decision matrix has been normalized to make it dimensionless in the range of 0 to 1 . This was done to transform the performance rating with different data measured in the decision matrix in order to facilitate the inter-criterion comparison. Normalized decision matrix on the basis of attributes (beneficiary or non-beneficiary) has been prepared by using Eqs. (2) and (3) as given below for PSI method.

- For beneficiary selection criterion

$$
r_{i j}=\frac{X_{i j}}{X_{j}^{\max }} \quad \text { for larger the better }
$$

- For non-beneficiary selection criterion

$$
\mathrm{r}_{\mathrm{ij}}=\frac{X_{j}^{\min }}{X_{i j}} \quad \text { for smaller the better }
$$

Step 4: Use of Entropy method for determining weight of the each performance deciding criterion

The weights are ascertained without the direct involvement of the decision maker. The basic concept of entropy method is that, importance of a criterion is direct function of the information conveyed by it relative to the whole set of alternatives [29]. The steps of the entropy method are-

Step 4a: Formulate a $\mathrm{M} \times \mathrm{N}$ decision matrix $\left(\mathrm{Eq}^{\mathrm{n}} 1\right)$, where $\mathrm{M}$ is the number of alternatives considered and $\mathrm{N}$ is the number of performance defining criterion.

Step $4 \mathrm{~b}$ : The normalized decision matrix has been formulated in order to facilitate comparison of all attributes and to get the projection value of alternatives $\left(P_{i j}\right)$. The formula used to normalize the attribute value is given by $\mathrm{Eq}^{\mathrm{n}}$ (4).

$$
P_{i j}=\frac{r_{i j}}{\sum_{i=1}^{m} r_{i j}}
$$

Step $4 \mathrm{c}$ : The entropy for $\mathrm{j}^{\text {th }}$ criterion has been calculated by using Eq. (5)

$$
E_{j}=-\mathrm{k} \sum_{j=1}^{m} P_{i j \ln P_{i j}}
$$

Where $\mathrm{k}$ is a constant and calculated as $\mathrm{k}=\frac{1}{\ln (M)}$.

Step 5: Obtain the weighted normalized matrix $\left[V_{j}\right]$ (by using Eq. (6)) to identify the relative importance of each criterion. The weights of the criterion are normalized to sum of one. Where $W_{j} \geq 0 ; \sum_{j=1}^{n} W_{j}=1$. The weighted normalized decision matrix is obtained by multiplying each element of the decision matrix by $E_{j}$.

$$
\left[V_{j}\right]=E_{j} \times r_{i j}
$$

Step 6: Identify the positive ideal solution $\left(\mathrm{A}^{+}\right)$and negative ideal solution $\left(\mathrm{A}^{-}\right)$based on the weighted normalized rating by using Eq. (7). PIS maximize the beneficiary criterion and minimize the non-beneficiary criterion, whereas NIS maximizes the non-beneficiary criterion and minimizes the beneficiary criterion.

$$
\begin{aligned}
& {\left[\mathrm{A}^{+}\right]=\left[V_{1}^{+}, V_{2}^{+}, V_{3}^{+}, \ldots V_{N}^{+}\right], \text {and }} \\
& {\left[\mathrm{A}^{-}\right]=\left[V_{1}^{-}, V_{2}^{-}, V_{3}^{-}, \ldots V_{N}^{-}\right]}
\end{aligned}
$$

where $\left[\mathrm{A}^{+}\right]=\left\{\begin{array}{l}\max V_{i j}, \text { if } \mathrm{j} \text { is benificiary criterion, } \\ \min V_{\mathrm{ij}}, \text { if } \mathrm{j} \text { is non-benificiary criterion }\end{array}\right\}$, and

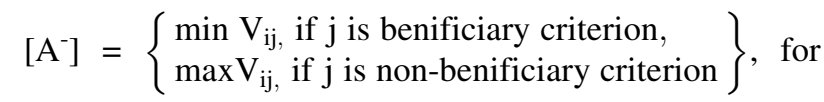
$\mathrm{j}=1,2,3, \ldots \mathrm{N}$

Step 7: Identify the Euclidian distance (by using Eqs.(8) and (9), which represents the distances of each alternative from positive $\left(\mathrm{D}^{+}\right)$and negative ideal solution $\left(\mathrm{D}^{-}\right)$. 


$$
\begin{gathered}
\mathrm{D}^{+}=\sqrt{\sum_{i=1}^{N}\left(V_{i}-V_{i j}\right)^{2}} \\
\mathrm{D}^{-}=\sqrt{\sum_{i=1}^{N}\left(V_{i j}-V_{j}\right)^{2},} \text { for } \mathrm{i}=1,2,3, \ldots, \mathrm{M}
\end{gathered}
$$

Step 8: Calculate the overall performance or closeness index value (CI) by using Eq. (10), which tells about the relative closeness of the given alternatives with respect to positive ideal solution.

$$
\mathrm{CI}=\frac{\mathrm{D}-}{D^{+}+D^{-}}
$$

Step 9: Now rank all the given alternatives in the descending order of performance index value (CI) that indicates the most and least preferred feasible solution.

Step 10: The final decision is made by appropriate consideration of possible constraints and finally the best alternative will be chosen based on high CI value.

The flowchart for the proposed hybrid TOPSIS-PSI method is shown in figure 1.

\section{Practical examples}

To demonstrate and validate the effectiveness of the proposed hybrid TOPSIS-PSI method, two practical examples of material selection are taken from literature.

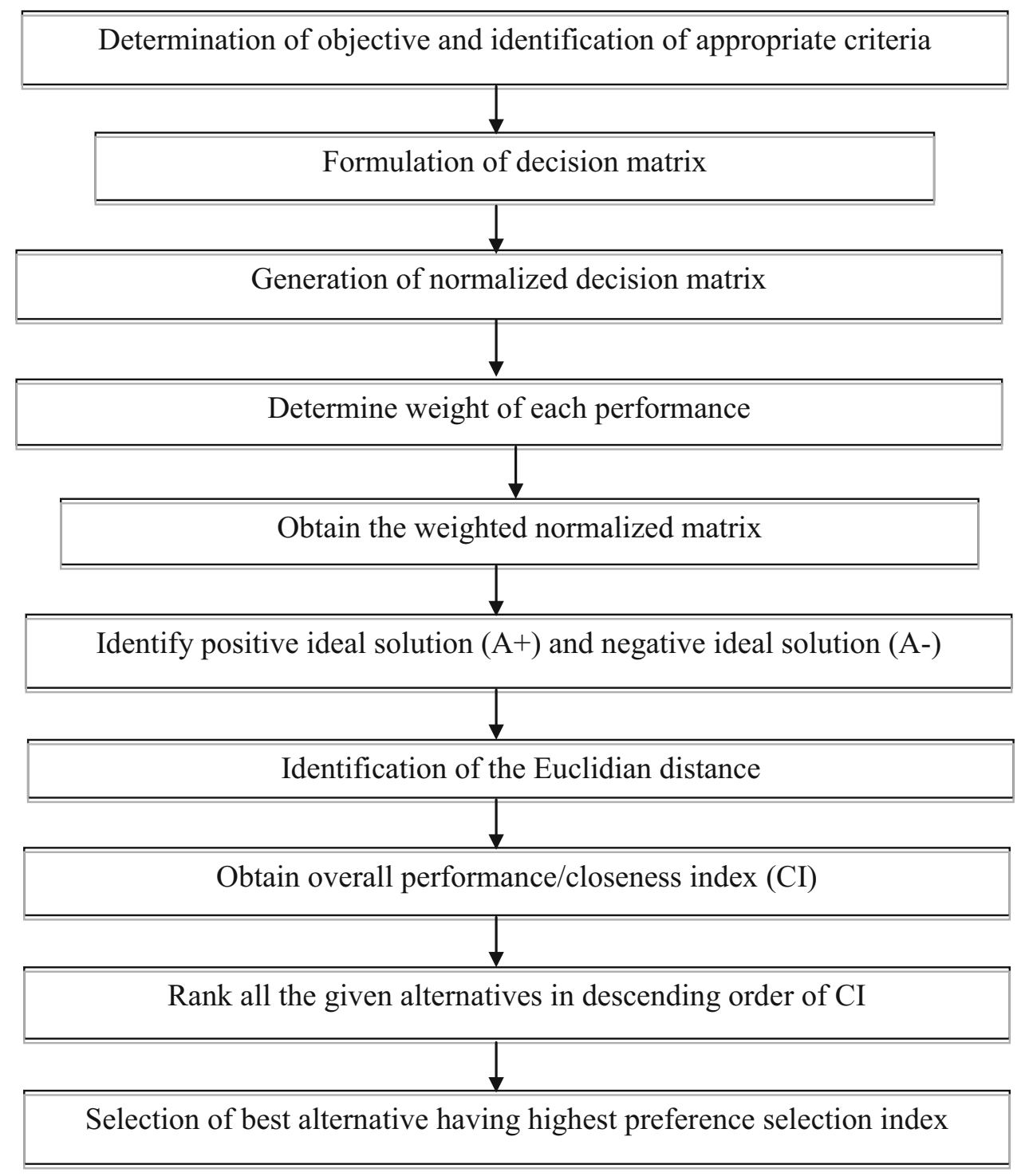

Figure 1. Flowchart of the proposed hybrid TOPSIS-PSI approach. 


\subsection{Example 1 (tool holder material selection)}

Caliskan et al [34] have applied different multi-criteria decision making methods for material selection problem of the tool holder working under hard milling conditions. They have used PROMETHEE II, TOPSIS and VIKOR method for material selection. In milling, there is a variation in cutting force which results from intermittent cutting. Therefore, the tool holder should have high stiffness and high energy dissipation rate. Moreover, the cost of the tool holder material should also have low values for a reasonable advantage among its manufacturers. There are no material available which meets all these specific demands. Therefore, it is necessary to choose the best alternative material that has the highest degree of satisfaction for all the relevant criteria. The problem considering nine alternatives and 6 material selection criteria are shown in table 1. Caliskan et al have obtained the data from CES EduPack software and the average values are used. Now the various steps of the proposed procedure are shown below:

Step 1: The objective is to find out the material for the tool holder working under hard milling conditions. The attributes considered are the same as used in Caliskan et al [34] are young modulus (YM), compressive strength (CS), fracture toughness (FT), mechanical loss coefficient (MLC), sufficient hardness (H) and cost (C). All these properties are beneficial attributes that require high values except for the cost factor which is non-beneficial attribute requiring least value. Nine different tool holder materials were taken into deliberation: AISI 1020 steel rolled, AISI 1040 steel tempered at $425^{\circ} \mathrm{C}$ and water quenched, AISI 4140 steel normalized, AISI 6150 steel tempered at $315^{\circ} \mathrm{C}$ and oil quenched, AISI 8620 steel normalized, maraging steel, AISI S5 tool steel (shock-resisting) tempered at $205^{\circ} \mathrm{C}$, tungsten carbide-cobalt $(10 \%), \mathrm{Fe}-5 \mathrm{Cr}-\mathrm{Mo}-\mathrm{V}$ aircraft steel quenched and tempered.

Step 2: The next step is to create a decision matrix and representation of all the attributes data in this matrix. The data given in the table 1 is arranged in the form of matrix but not shown here due to space constraint.

Step 3: The quantitative data provided in table 1 is normalized using Eqs. (2) and (3). The matrix has been shown in table 2.

Step 4: The next step is to determine the objective weights of the different criteria which areshown in table 3 . From the below weights, it is clear that cost and young modulus are the most important criteria. On the contrary, the least significant criterion is found to be compressive strength.

Table 3. Weight determination by applying Entropy method using Eqs. (5a) and (5b).

\begin{tabular}{lcccccc}
\hline Material & YM & CS & FT & MLC & H (HV) & C \\
\hline W & 0.194 & 0.067 & 0.141 & 0.128 & 0.131 & 0.340 \\
\hline
\end{tabular}

Table 1. Quantitative data of tool holder material and the alternatives.

\begin{tabular}{|c|c|c|c|c|c|c|}
\hline Material & YM (GPa) & $\mathrm{CS}(\mathrm{MPa})$ & $\mathrm{FT}(\mathrm{MPa} \mathrm{m})^{1 / 2}$ & MLC & $\mathrm{H}(\mathrm{HV})$ & $\mathrm{C}(\$ / \mathrm{kg})$ \\
\hline AISI $1020(1)$ & 210 & 330 & 54.5 & 0.00111 & 150 & 0.673 \\
\hline AISI 1040 (2) & 212 & 632.5 & 46 & 0.00117 & 355 & 0.7045 \\
\hline AISI 4140 (3) & 212 & 655 & 87.5 & 0.000515 & 305 & 0.864 \\
\hline AISI 6150 (4) & 206.5 & 1575 & 38 & 0.00026 & 483 & 1.175 \\
\hline AISI $8620(5)$ & 206.5 & 360 & 111.5 & 0.00089 & 190 & 0.8665 \\
\hline Maraging steel (6) & 187.5 & 1825 & 80 & 0.00071 & 532.5 & 6.97 \\
\hline AISI S5 (7) & 210 & 1930 & 21 & 0.0000205 & 771 & 7.99 \\
\hline Tungsten carbide-cobalt (8) & 593 & 4405 & 14.05 & 0.00135 & 1250 & 79.6 \\
\hline $\mathrm{Fe}-5 \mathrm{Cr}-\mathrm{Mo}-\mathrm{V}$ (9) & 212.5 & 1655 & 120 & 0.00113 & 448.5 & 1.73 \\
\hline
\end{tabular}

Table 2. Normalized decision matrix.

\begin{tabular}{lccccc}
\hline Material & YM $(\mathrm{GPa})$ & $\mathrm{CS}(\mathrm{MPa})$ & FT $(\mathrm{MPa} \mathrm{m})^{1 / 2}$ & MLC & $\mathrm{H}(\mathrm{HV})$ \\
\hline 1 & 0.3541 & 0.0749 & 0.4542 & 0.8222 & 0.12 \\
2 & 0.3575 & 0.1436 & 0.3833 & 0.8667 & 0.284 \\
3 & 0.3575 & 0.1487 & 0.7292 & 0.3815 & 0.244 \\
4 & 0.3482 & 0.3575 & 0.3167 & 0.1926 & 0.3864 \\
5 & 0.3482 & 0.0817 & 0.9292 & 0.6593 & 0.152 \\
6 & 0.3162 & 0.4143 & 0.6667 & 0.5259 & 0.426 \\
7 & 0.3541 & 0.4381 & 0.9344 & 0.0181 & 0.6168 \\
8 & 1 & 1 & 0.175 & 1 & 0.7728 \\
9 & 0.3583 & 0.3757 & 1 & 0.837 & 0.0966 \\
\hline
\end{tabular}


Table 4. Weighted normalized decision matrix.

\begin{tabular}{|c|c|c|c|c|c|c|}
\hline Material & $\mathrm{YM}(\mathrm{GPa})$ & $\mathrm{CS}(\mathrm{MPa})$ & FT $(\mathrm{MPa} \mathrm{m})^{1 / 2}$ & MLC & $\mathrm{H}(\mathrm{HV})$ & $\mathrm{C}(\$ / \mathrm{kg})$ \\
\hline 1 & 0.0687 & 0.0670 & 0.0640 & 0.1052 & 0.0157 & 0.3400 \\
\hline 2 & 0.0694 & 0.0620 & 0.0540 & 0.1109 & 0.0372 & 0.3248 \\
\hline 3 & 0.0694 & 0.0617 & 0.1028 & 0.0488 & 0.0320 & 0.2648 \\
\hline 4 & 0.0675 & 0.0465 & 0.0447 & 0.0247 & 0.0506 & 0.1948 \\
\hline 5 & 0.0675 & 0.0665 & 0.1310 & 0.0844 & 0.0199 & 0.2641 \\
\hline 6 & 0.0613 & 0.0424 & 0.0940 & 0.0673 & 0.0558 & 0.0328 \\
\hline 7 & 0.0687 & 0.0407 & 0.1318 & 0.0023 & 0.0808 & 0.0286 \\
\hline 8 & 0.194 & 0.0000 & 0.0247 & 0.1280 & 0.1310 & 0.0029 \\
\hline 9 & 0.0695 & 0.0452 & 0.1410 & 0.1071 & 0.0470 & 0.1323 \\
\hline PIS $(\mathrm{A}+)$ & 0.194 & 0.0665 & 0.1410 & 0.1280 & 0.1310 & 0.0029 \\
\hline PIS (A-) & 0.0613 & 0 & 0.0247 & 0.0023 & 0.0157 & 0.3400 \\
\hline
\end{tabular}

Step 5: The next step is calculation of weighted normalized decision matrix (see table 4), which is determined using Eq. (6).

Step 6: The next step is determination of the positive ideal solution $\left(\mathrm{A}^{+}\right)$and negative ideal solution $\left(\mathrm{A}^{-}\right)$based on the weighted normalized rating by using Eq. ${ }^{\mathrm{n}}$ (7).

Step 7: Further, the Euclidian distances of each alternative from positive $\left(\mathrm{D}^{+}\right)$and negative ideal solution $\left(\mathrm{D}^{-}\right)$has been determined by using Eqs. (8) and (9) and from these the relative closeness of the given alternatives with respect to positive ideal solution has been calculated by using Eq. (10) and shown in table 5. Furthermore, table 5 shows the ranking order of different alternatives using hybrid TOPSIS-PSI method. The ranking shows that Tungstencarbide-cobalt is the first choice because of its better mechanical properties except for the fracture toughness value for the given design application. The second choice as predicted by hybrid TOPSIS-PSI is Maraging steel. This may be because of low cost and higher value of fracture toughness. This was not predicted by other methods as clearly seen in below figure 2 . The worst choice AISI S5 (7) which is confirmed by all the other methods. The choice predicted are based on six attributes, which is chosen among best nine alternatives. Moreover, the result matches well with that suggested by Caliskan et al by using various MADM methods (EXPROM2, TOPSIS and VIKOR) as

Table 5. Performance index and ranking of nano-composites.

\begin{tabular}{llclc}
\hline Compositions & \multicolumn{1}{c}{$\mathrm{D}^{+}$} & \multicolumn{1}{c}{$\mathrm{D}^{-}$} & \multicolumn{1}{c}{$\mathrm{CI}$} & Ranking \\
\hline 1 & 0.03543 & 0.11439 & 0.763516 & $\mathbf{3}$ \\
2 & 0.13583 & 0.01726 & 0.241836 & $\mathbf{5}$ \\
3 & 0.1017 & 0.01806 & 0.150802 & $\mathbf{7}$ \\
4 & 0.07963 & 0.02540 & 0.112744 & $\mathbf{8}$ \\
5 & 0.09857 & 0.02828 & 0.22294 & $\mathbf{6}$ \\
6 & 0.0306 & 0.10681 & 0.777309 & $\mathbf{2}$ \\
7 & 0.14908 & 0.01668 & 0.100627 & $\mathbf{9}$ \\
8 & 0.01795 & 0.16034 & 0.899321 & $\mathbf{1}$ \\
9 & 0.04019 & 0.07074 & 0.637699 & $\mathbf{4}$ \\
\hline
\end{tabular}

The bold shows the final ranking of materials. shown in table 6 and figure 2. The hybrid method uses advantage of PSI and TOPSIS that includes the concept of statistics, which may be helpful to the decision makers having weak mathematics background. The computational time requirement of the PSI method is very much less as compared to other MCDM methods.

\subsection{Example 2 (gas welding process selection)}

Rao [35] in his study applied fuzzy PROMETHEE and fuzzy ANP for selecting the best arc welding process in joining the mild steel workpiece. The alternative available were SMAW, GTAW and GMAW. The problem considering three above alternatives and 6 criteria are shown in table 7 . The criteria considered include weld quality (WQ), skill required $(\mathrm{SR})$, cleaning required $(\mathrm{CR})$, operator fatigue (OF), consumables availability (CA), and initial preparation (IP). Now the various steps of the proposed procedure are shown below.

Step 1: The objective is to find out the best arc welding process among the three alternative and six criteria considered shown in table 7. The beneficial attributes are SR, $\mathrm{CR}$, OF and IP and non-beneficial are WQ and CA.

Step 2: The next step is to create a decision matrix and representation of all the attributes data in this matrix.

Step 3: The quantitative data provided in the table 7 is normalized using Eqs. (2) and (3). The matrix has been shown in table 8 .

Step 4: The next step is weight determination of each criterion using Eqs. (5a) and (5b)

\begin{tabular}{lcccccc}
\hline Process & WQ & SR & CR & OF & CA & IP \\
\hline $\mathrm{W}$ & 0.0836 & 0.1413 & 0.1231 & 0.3924 & 0.2015 & 0.0581 \\
\hline
\end{tabular}

Step 5: The normalized weighted decision matrix is shown in table 9. 


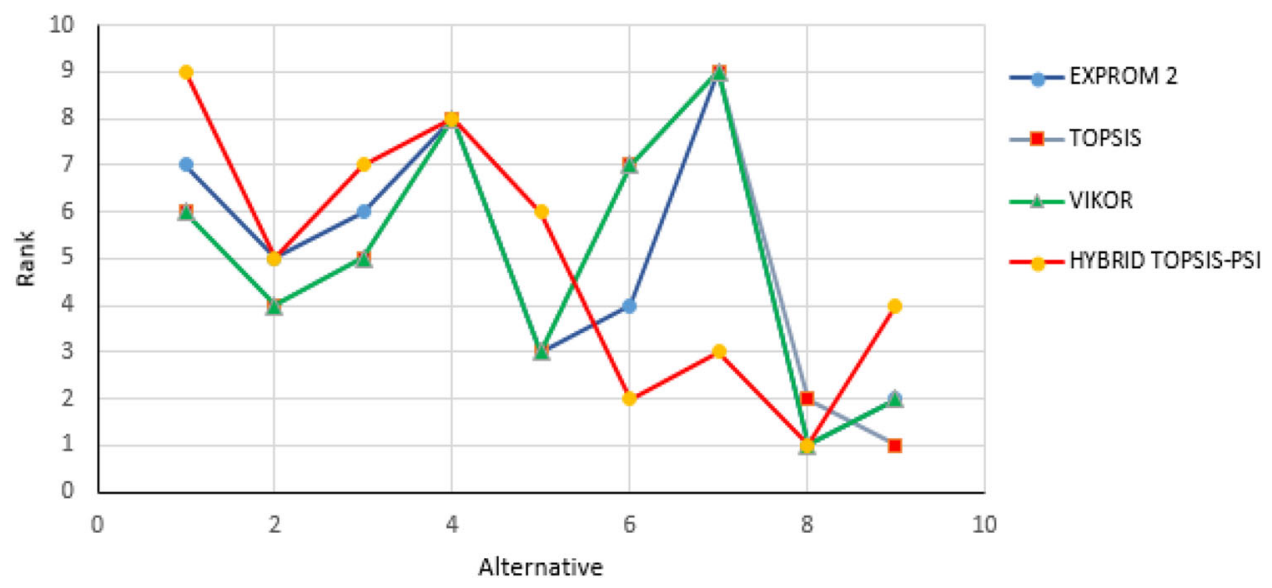

Figure 2. Comparison of ranking with different methods used in literature

Table 6. Comparison of rank results with literature.

\begin{tabular}{lcccc}
\hline Material & EXPROM 2 & TOPSIS & VIKOR & $\begin{array}{c}\text { Hybrid } \\
\text { TOPSIS-PSI }\end{array}$ \\
\hline 1 & 7 & 6 & 6 & 9 \\
2 & 5 & 4 & 4 & 5 \\
3 & 6 & 5 & 5 & 7 \\
4 & 8 & 8 & 8 & 8 \\
5 & 3 & 3 & 3 & 6 \\
6 & 4 & 7 & 7 & 2 \\
7 & 9 & 9 & 9 & 3 \\
8 & 1 & 2 & 1 & 1 \\
9 & 2 & 1 & 2 & 4 \\
\hline
\end{tabular}

Table 7. Qualitative data for arc welding process selection from Rao [35].

\begin{tabular}{lcccccc}
\hline Process & WQ & SR & CR & OF & CA & \multicolumn{1}{c}{ IP } \\
\hline SMAW (1) & 210 & 330 & 54.5 & 0.00111 & 150 & 0.673 \\
GTAW (2) & 212 & 632.5 & 46 & 0.00117 & 355 & 0.7045 \\
GMAW (3) & 212 & 655 & 87.5 & 0.000515 & 305 & 0.864 \\
\hline
\end{tabular}

Step 6: The next step is determination of the positive ideal solution $\left(\mathrm{A}^{+}\right)$and negative ideal solution $\left(\mathrm{A}^{-}\right)$based on the weighted normalized rating by using Eq. (6).Step 7: Further, the Euclidian distances of each alternative from positive $\left(\mathrm{D}^{+}\right)$and negative ideal solution $\left(\mathrm{D}^{-}\right)$has been determined by using Eqs.(7) and (8) and from these the relative closeness of the given alternatives with respect to positive ideal solution has been calculated by using Eq. (9) and shown in table 10. Furthermore, table 10 shows the ranking order of different alternatives using hybrid TOPSIS-PSI method.

Step 8: Based on the ranking provided in table 10, it can be clearly seen that submerged arc welding (SMAW) is the best of the three welding processes and gas tungsten arc welding (GTAW) is the least choice. The studies of Rao [35], Attri and Grover [12] also predicted that SMAW is the best welding process among the three by using graph theory, AHP and PSI technique. The comparison among the different literature is shown in table 10, which clearly suggests that the proposed hybrid procedure provides effectively good results.

Therefore, the proposed hybrid TOPSIS-PSI method is very much providing comparable results and can be used for material selection in any application. Now, the proposed hybrid TOPSIS-PSI procedure is used for selecting the material in marine application in this study.

\section{Experimental details}

In this study, most appropriate material need to be selected for marine application among alternatives of four given hybrid aluminium nanocomposite. The hybrid TOPSIS-PSI procedure is used for choosing the best alternative. The

Table 8. Normalized decision matrix.

\begin{tabular}{lccccc}
\hline Process & WQ & SR & CR & OF & CA \\
\hline SMAW (1) & 1 & 0.5038 & 0.6228 & 0.09487 & 1 \\
GTAW (2) & 0.9906 & 0.9656 & 0.5257 & 1 & 0.7789 \\
GMAW (3) & 0.9906 & 1 & 1 & 0.4401 & 0.4225 \\
\hline
\end{tabular}


Table 9. Normalized weighted decision matrix.

\begin{tabular}{lcccccc}
\hline Process & WQ & SR & CR & OF & CA & IP \\
\hline SMAW (1) & 0.0828 & 0.1364 & 0.0647 & 0.3924 & 0.0851 & 0.0473 \\
GTAW (2) & 0.0836 & 0.0712 & 0.0777 & 0.0372 & 0.2015 & 0.0453 \\
GMAW (3) & 0.0828 & 0.1413 & 0.1213 & 0.1727 & 0.099 & 0.0581 \\
PIS (A+) & 0.0828 & 0.1413 & 0.1213 & 0.3924 & 0.0851 & 0.0581 \\
NIS (A-) & 0.0836 & 0.0712 & 0.0647 & 0.0372 & 0.2015 \\
\hline
\end{tabular}

Table 10. Ranking comparison of different processes with literature.

\begin{tabular}{lllcccc}
\hline Process & \multicolumn{1}{c}{$\mathrm{D}^{+}$} & \multicolumn{1}{c}{$\mathrm{D}^{-}$} & $\mathrm{CI}$ & Ranking & $\begin{array}{l}\text { Rao } \\
\text { et al } \\
{[35]}\end{array}$ & $\begin{array}{c}\text { Attri } \\
\text { et al } \\
{[12]}\end{array}$ \\
\hline 1 & 0.0578 & 0.3794 & 0.8677 & $\mathbf{1}$ & $\mathbf{1}$ & $\mathbf{1}$ \\
2 & 0.3830 & 0.013 & 0.0328 & $\mathbf{3}$ & $\mathbf{3}$ & $\mathbf{2}$ \\
3 & 0.2201 & 0.1927 & 0.4668 & $\mathbf{2}$ & $\mathbf{2}$ & $\mathbf{3}$ \\
\hline
\end{tabular}

The bold shows the final ranking of materials.

matrix and reinforcing materials used for the fabrication of composite has been shown in table 11 .

\subsection{Fabrication of composites}

Stir casting technique has been used for the fabrication of hybrid aluminum nanocomposite because of its higher material yield and low initial cost as compared to other process. In this process, the reinforcing phases were dispersed in to molten matrix metal by mechanical stirring. Chemical composition of the designed composites has been shown in table 12. The process of preparation for hybrid aluminium composite plates has been shown in figure 3 .

\subsection{Characterization of hybrid aluminium nanocomposite}

The hybrid aluminium nanocomposite has been characterized by performing physical, mechanical and corrosion test (in $3.5 \% \mathrm{NaCl}$ solution) of the fabricated composite. These tests have been conducted on the well prepared specimen to investigate the effect of ceramic reinforcements in the pure aluminium for marine conditions. The result obtained by performing several experiments has been shown in table 13 .
Table 12. Chemical compositions of the designed composites.

\begin{tabular}{lcc}
\hline $\begin{array}{l}\text { Sl. } \\
\text { No }\end{array}$ & Compositions & $\begin{array}{c}\text { Combined } \\
\text { reinforcement wt.\% }\end{array}$ \\
\hline 1 & $100 \% \mathrm{Al}+0 \% \mathrm{SiC}+0 \% \mathrm{Gr}+0 \% \mathrm{ZrO}_{2}$ & $0 \% \mathrm{SGZr}$ \\
2 & $97 \% \mathrm{Al}+1 \% \mathrm{SiC}+1 \% \mathrm{Gr}+1 \% \mathrm{ZrO}_{2}$ & $3 \% \mathrm{SGZr}$ \\
3 & $94 \% \mathrm{Al}+2 \% \mathrm{SiC}+2 \% \mathrm{Gr}+2 \% \mathrm{ZrO}_{2}$ & $6 \% \mathrm{SGZr}$ \\
4 & $91 \% \mathrm{Al}+3 \% \mathrm{SiC}+3 \% \mathrm{Gr}+3 \% \mathrm{ZrO}_{2}$ & $9 \% \mathrm{SGZr}$ \\
\hline
\end{tabular}

The selection criteria of the attributes for the formulation of decision matrix on the basis of beneficiary and nonbeneficiary criteria has been given in table 14 .

Step 1: Formulation of decision matrix for hybrid aluminum nanocomposite

This decision matrix consists of six attributes and four hybrid reinforcement wt.\% alternatives that explained in table 14. Experimental results of the attributes (mechanical and corrosion testing results) have been used for the formulation of the decision matrix i.e., shown in table 15 . Here void contents (VC) and (corrosion current density) CCD have non-beneficiary criterion and remaining have beneficiary criterion.

Step 2: Normalized decision matrix for hybrid aluminium nanocomposite

Normalized decision matrix for hybrid aluminium nanocomposite has been prepared by using Eqs. (2) and (3). The matrix has been shown in table 16 .

\subsection{Determination of weights using entropy method}

In this step, entropy and dispersion value for $\mathrm{j}^{\text {th }}$ criterion has been calculated and then weight of the each performance deciding criterion has been calculated from obtained dispersion value using Eqs. (5) and (6). All the values are shown in table 17.

Table 11. Selected matrix materials and reinforcements for composite fabrication.

\begin{tabular}{lccr}
\hline Sl.No. & Matrix materials & Reinforcements & Size of reinforcements \\
\hline 1. & Pure Aluminium $(98.8 \% \mathrm{Al})$ & Silicon carbide $(\mathrm{SiC})$ & $40-50$ micrometers \\
2. & - & Graphite $(\mathrm{Gr})$ & $40-50$ micrometers \\
3. & - & Zirconia $\left(\mathrm{ZrO}_{2}\right)$ & $40-50$ nanometers \\
\hline
\end{tabular}



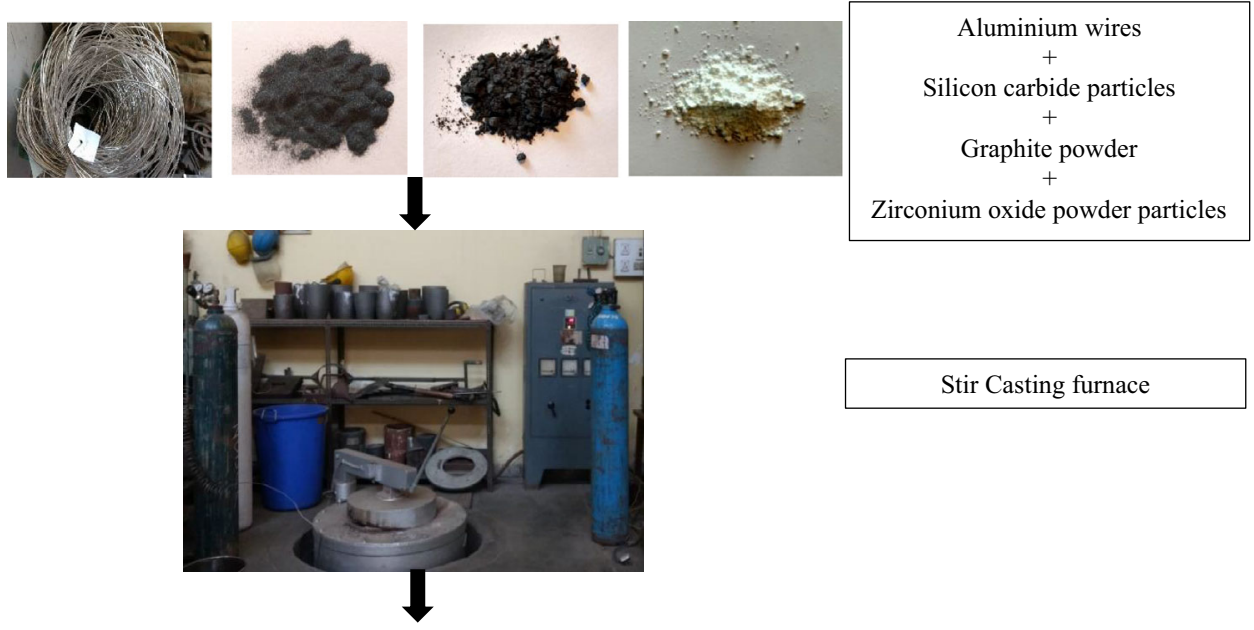

Zirconium oxide powder particles

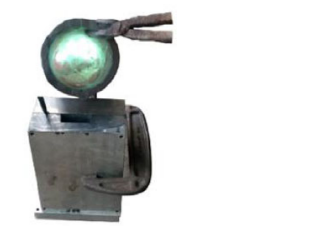

Pouring of molten mixture into mold

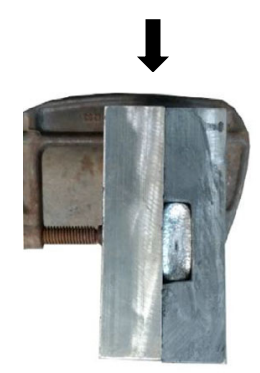

Solidified composite plate

Figure 3. Aluminium nanocomposite plate preparation.

Table 13. Results of the physical, mechanical and corrosion testing.

\begin{tabular}{|c|c|c|c|c|c|c|}
\hline \multirow[b]{2}{*}{ Composites } & \multirow{2}{*}{$\begin{array}{c}\text { Physical characterization } \\
\text { Void contents } \\
(\%)\end{array}$} & \multicolumn{4}{|c|}{ Mechanical characterization } & \multirow{2}{*}{$\begin{array}{c}\text { Corrosion } \\
\text { characterization } \\
\text { Corrosion } \\
\text { current density } \\
\left(\mu \mathrm{A} / \mathrm{cm}^{2}\right)\end{array}$} \\
\hline & & $\begin{array}{l}\text { Hardness } \\
(\mathrm{VHN})\end{array}$ & $\begin{array}{c}\text { Tensile strength } \\
(\mathrm{MPa})\end{array}$ & $\begin{array}{l}\text { Flexural strength } \\
\qquad(\mathrm{MPa})\end{array}$ & $\begin{array}{c}\text { Charpy impact test } \\
(\mathrm{MPa})\end{array}$ & \\
\hline $\mathrm{Al}+0 \% \mathrm{SGZr}$ & 2.360 & 33.354 & 115.092 & 177.38 & 195.02 & 0.481 \\
\hline $\mathrm{Al}+3 \% \mathrm{SGZr}$ & 1.714 & 42.58 & 108.979 & 141.20 & 242.06 & 0.403 \\
\hline $\mathrm{Al}+6 \% \mathrm{SGZr}$ & 2.240 & 37.99 & 91.7182 & 160.76 & 247.94 & 1.040 \\
\hline $\mathrm{Al}+9 \% \mathrm{SGZr}$ & 1.751 & 39.45 & 123.949 & 146.46 & 242.06 & 8.950 \\
\hline
\end{tabular}

After the normalization of the decision matrix, a weighted decision matrix has been calculated by using Eq. (5) and given in table 18.

And then the Euclidian distances of each alternative from positive $\left(\mathrm{D}^{+}\right)$and negative ideal solution $\left(\mathrm{D}^{-}\right)$has been determined by using Eqs. (7) and (8) and from these the relative closeness of the given alternatives with respect to positive ideal solution has been calculated by using Eq. (9) and shown in table 19.

These indexes values are then arranged in descending order and best alternative on the basis of selected criterion is ranked by higher performance index value. The ranking order is given by $9 \% \mathrm{SGZr}>6 \% \mathrm{SGZr}>0 \% \mathrm{SGZr}>3 \%$ SGZr. So, on the basis of hybrid TOPSIS-PSI methodology 
Table 14. Selected criteria for the attributes of the hybrid aluminum nanocomposites.

\begin{tabular}{lcc}
\hline Sl. No. & Attributes & Selection criteria of attributes \\
\hline 1 & Void contents (VC) & Non-beneficial attribute (Lower the better) \\
2 & Hardness (H) & Beneficiary attribute (Higher the better) \\
3 & Tensile strength (TS) & Beneficiary attribute (Higher the better) \\
4 & Flexural strength (FS) & Beneficiary attribute (Higher the better) \\
5 & Charpy Impact strength (CIS) & Beneficiary attribute (Higher the better) \\
6 & Corrosion current density (CCD) & Non-beneficial attribute (Lower the better) \\
\hline
\end{tabular}

Table 15. Decision matrix for hybrid aluminium nanocomposite.

\begin{tabular}{lccrrr}
\hline Composites & VC & H & TS & FS & CIS \\
\hline AL+0\% SGZr & 2.360 & 33.354 & 115.0929 & 177.38 & 195.02 \\
AL+3\% SGZr & 1.714 & 42.58 & 108.9797 & 141.20 & 242.06 \\
AL+6\% SGZr & 2.240 & 37.99 & 91.7182 & 160.76 & 247.94 \\
AL+9\% SGZr & 1.751 & 39.45 & 123.9495 & 146.46 & 242.06 \\
\hline
\end{tabular}

Table 16. Normalized decision matrix for hybrid aluminum nanocomposite.

\begin{tabular}{lcccccc}
\hline Composites & VC & H & TS & FS & CIS & CCD \\
\hline $\mathrm{Al}+0 \%$ SGZr & 0.7263 & 0.7832 & 0.9285 & 1 & 0.7856 \\
$\mathrm{Al}+3 \%$ SGZr & 1 & 1 & 0.8792 & 0.7960 & 0.9763 & 1 \\
$\mathrm{Al}+6 \%$ SGZr & 0.7652 & 0.8922 & 0.7399 & 0.9063 & 0.8383 \\
$\mathrm{Al}+9 \%$ SGZr & 0.9788 & 0.9264 & 1 & 0.8257 & 0.9763 \\
\hline
\end{tabular}

Table 17. Criterion weights determined by entropy method.

\begin{tabular}{lccc}
\hline $\begin{array}{l}\text { Performance } \\
\text { defining criterion }\end{array}$ & $\mathrm{E}_{\mathrm{j}}$ & $\mathrm{DP}_{\mathrm{j}}$ & $\mathrm{W}_{\mathrm{j}}$ \\
\hline $\mathrm{VC}$ & 0.9920 & 0.008 & 0.014 \\
$\mathrm{H}$ & 0.9950 & 0.005 & 0.009 \\
$\mathrm{TS}$ & 0.9956 & 0.005 & 0.009 \\
$\mathrm{FS}$ & 0.9970 & 0.003 & 0.005 \\
CIS & 0.9967 & 0.004 & 0.007 \\
CCD & 0.4649 & 0.535 & 0.955 \\
\hline
\end{tabular}

it can be concluded that $9 \%$ SGZr will be the first choice for the marine application of the composites, and then $6 \%$ SGZr and so on which is mainly due to high corrosion current density that is the most important criteria to sustain in marine life. In addition, the $9 \%$ SGZr nanocomposite has high tensile strength of $123.949 \mathrm{MPa}$ that will assist in giving longer life to the marine structures without failure. The low void contents $\%$ as compared to other materials is also needed in marine applications as the low specific density helps the material to float in the marine conditions as higher void content can lead to greater susceptibility to water penetration. The flexural strength of $9 \% \mathrm{SGZr}$ is higher than the tensile strength which is also significant as it will help in improving the life of material in marine applications. The selected nano-composite due to its higher impact strength can be widely used for high performance impact resistance applications. They can also be used in many marine applications like hull materials of small boats and also in the defence sector as impact resistant structures. From the above discussion, it can be concluded that the $9 \%$

Table 18. Normalized weighted decision matrix.

\begin{tabular}{lllllrr}
\hline Composites & VC & H & TS & FS & CIS & CCD \\
\hline Weights & 0.014 & 0.009 & 0.009 & 0.005 & 0.007 & 0.955 \\
Al+0\% SGZr & 0.0102 & 0.0070 & 0.0083 & 0.0050 & 0.0055 & 0.8005 \\
Al+3\% SGZr & 0.0140 & 0.0090 & 0.0079 & 0.0039 & 0.0068 & 0.9550 \\
Al+6\% SGZr & 0.0107 & 0.0080 & 0.0066 & 0.0045 & 0.0070 & 0.3702 \\
Al+9\% SGZr & 0.0137 & 0.0083 & 0.0090 & 0.0041 & 0.0068 & 0.0430 \\
PIS (A ${ }^{+}$) & 0.0102 & 0.009 & 0.009 & 0.005 & 0.007 & 0.0430 \\
NIS $\left(\mathrm{A}^{-}\right)$ & 0.014 & 0.007 & 0.0066 & 0.0039 & 0.0055 & 0.9550 \\
\hline
\end{tabular}


Table 19. Closeness index and ranking of nano composites.

\begin{tabular}{lcclc}
\hline Compositions & $\mathrm{D}^{+}$ & \multicolumn{1}{c}{$\mathrm{D}^{-}$} & \multicolumn{1}{c}{$\mathrm{CI}$} & Ranking \\
\hline $\mathrm{Al}+0 \% \mathrm{SGZr}$ & 0.7574 & 0.1545 & 0.1694 & $\mathbf{3}$ \\
$\mathrm{Al}+3 \% \mathrm{SGZr}$ & 0.9119 & 0.0027 & 0.00298 & $\mathbf{4}$ \\
$\mathrm{Al}+6 \% \mathrm{SGZr}$ & 0.3271 & 0.5850 & 0.6413 & $\mathbf{2}$ \\
$\mathrm{Al}+9 \% \mathrm{SGZr}$ & 0.0036 & 0.9119 & 0.9959 & $\mathbf{1}$ \\
\hline
\end{tabular}

The bold shows the final ranking of materials.

SGZr nanocomposite chosen using hybrid TOPSIS-PSI approach is well-matched the criteria required by materials in marine applications.

\section{Conclusions}

In this paper, a novel hybrid TOPSIS-PSI methodology is proposed which helps in choosing the best alternative material in marine conditions which was carried out for hybrid aluminium nano composites. The advantages of both the techniques (TOPSIS and PSI) were considered and a logical procedure was developed. The PSI method has significance when there is struggle in deciding the relative importance among considered variables. The TOPSIS method is more proficient in dealing with the physical attributes and the number of available alternatives. However, TOPSIS method requires an effective methodology to evaluate the relative significance among different criteria with reference to the given objective and PSI method provides such an efficient methodology. The weights of the selected criteria for hybrid TOPSIS-PSI analysis have been determined by entropy method. For testing the methodology, two practical examples were considered from literature and the results obtained from hybrid TOPSI-PSI method is compared with the results derived by the past researchers. In all the cases, it is observed that best alternative exactly matches with those derived by the past researchers.

Furthermore, suitable material is chosen from a set of available aluminium nanocomposite. The obtained ranking order of the hybrid TOPSIS-PSI method was $9 \% \mathrm{SGZr}>$ $6 \% \mathrm{SGZr}>0 \% \mathrm{SGZr}>3 \% \mathrm{SGZr}$. Empirical findings in this study shows that $9 \%$ SGZr would be the first choice according to TOPSIS-PSI analysis, which have the best combination of physical and mechanical properties along with the good corrosion resistance of composite in the 3.5\% $\mathrm{NaCl}$ solution. So it can be concluded that $9 \mathrm{wt}$.\% of hybrid aluminium nanocomposites have optimum properties and cost advantages that can fulfill the requirements of marine as well as some other application areas such as automotive and industrial application that include in small fishing boats, ladders, hand rails, flooring, cladding, offshore bridges connecting between platforms, small engine cylinder heads and cylinder blocks (air cooled engines), coolant radiators (radiator fins), car bumpers, etc.

\section{References}

[1] Ashby M F, Brechet Y J M, Cebon D and Salvo L 2004 Selection strategies for materials and processes. Materials \& Design 25(1): 51-67

[2] Edwards K L 2005 Selecting materials for optimum use in engineering components. Materials \& Design 26(5): 469-473

[3] Thakker A, Jarvis J, Buggy M and Sahed A 2008 A novel approach to materials selection strategy case study: Wave energy extraction impulse turbine blade. Materials \& Design 29(10): 1973-1980

[4] Chatterjee P and Chakraborty S 2012 Material selection using preferential ranking methods. Materials \& Design 35 : 384-393

[5] Edwards K L 2011 Materials influence on design: a decade of development. Materials \& Design 32(3): 1073-1080

[6] Devaraju A, Kumar A, Kumaraswamy A and Kotiveerachari B 2013 Influence of reinforcements ( $\mathrm{SiC}$ and $\mathrm{Al}_{2} \mathrm{O}_{3}$ ) and rotational speed on wear and mechanical properties of aluminum alloy 6061-T6 based surface hybrid composites produced via friction stir processing. Materials \& Design 51: 331-341

[7] Seah K H W, Tucci A, Sharma S C, Girish B M and Kamath R 1995 Mechanical properties of cast lead alloy/silicon carbide particulate composites. Materials \& Design 16(6): 367-371

[8] Dinaharan I, Murugan N and Parameswaran S 2011 Influence of in situ formed $\mathrm{ZrB} 2$ particles on microstructure and mechanical properties of AA6061 metal matrix composites. Materials Science and Engineering: A 528(18): 5733-5740.

[9] McCafferty E 2010 Societal Aspects of Corrosion. In: Introduction to Corrosion Science New York, NY: Spreinger pp. 1-11

[10] Bobić B, Mitrović S, Babić M and Bobić I 2010 Corrosion of metal-matrix composites with aluminium alloy substrate. Tribology in Industry 32(1): 3-11

[11] Chamoli S 2015 Preference selection index approach for optimization of $\mathrm{V}$ down perforated baffled roughened rectangular channel. Energy 93: 1418-1425

[12] Attri R and Grover S 2015 Application of preference selection index method for decision making over the design stage of production system life cycle. Journal of King Saud University-Engineering Sciences 27(2): 207-216

[13] Bharath V, Nagaral M, Auradi V and Kori S A 2014 Preparation of 6061Al-A12O3 MMC's by Stir Casting and Evaluation of Mechanical and Wear Properties. Procedia Materials Science 6: 1658-1667

[14] Bhandare R G and Sonawane P M 2013 Preparation of aluminium matrix composite by using stir casting method. International Journal of Engineering and Advanced Technology 3(2): 61-65

[15] Khorshidi R, and Hassani A 2013 Comparative analysis between TOPSIS and PSI methods of materials selection to achieve a desirable combination of strength and workability in $\mathrm{Al} / \mathrm{SiC}$ composite. Materials \& Design (1980-2015) 52: 999-1010

[16] Diyaley S, Shilal P, Shivakoti I, Ghadai R K and Kalita K 2017 PSI and TOPSIS Based Selection of Process Parameters 
in WEDM. Periodica Polytechnica Engineering Mechanical Engineering 61(4): 255

[17] Ashby M F and Cebon D 1993 Materials selection in mechanical design. Le Journal de Physique IV 3(C7): C7-1

[18] Ashby M F and Johnson K 2013 Materials and design: the art and science of material selection in product design. Butterworth-Heinemann

[19] Maniya K and Bhatt M G 2010 A selection of material using a novel type decision-making method: Preference selection index method. Materials \& Design 31(4): 1785-1789

[20] Shanian A and Savadogo O 2006 A material selection model based on the concept of multiple attribute decision making. Materials \& Design 27(4): 329-337

[21] Karande P, Gauri S K and Chakraborty S 2013 Applications of utility concept and desirability function for materials selection. Materials \& Design 45: 349-358

[22] Zhou C C, Yin G F and Hu X B 2009 Multi-objective optimization of material selection for sustainable products: artificial neural networks and genetic algorithm approach. Materials \& Design 30(4): 1209-1215

[23] Chan J W and Tong T K 2007 Multi-criteria material selections and end-of-life product strategy: Grey relational analysis approach. Materials \& Design 28(5): 1539-1546

[24] Mansor M R, Sapuan S M, Zainudin E S, Nuraini A A and Hambali A 2013 Hybrid natural and glass fibers reinforced polymer composites material selection using Analytical Hierarchy Process for automotive brake lever design. Materials \& Design 51: 484-492

[25] Maity SR, Chatterjee P and Chakraborty S 2012 Cutting tool material selection using grey complex proportional assessment method. Materials \& Design (1980-2015) 36: 372-378

[26] Chatterjee P, Athawale, V M and Chakraborty S 2011 Materials selection using complex proportional assessment and evaluation of mixed data methods. Materials \& Design 32(2): 851-860
[27] Chakraborty S 2011 Applications of the MOORA method for decision making in manufacturing environment. The International Journal of Advanced Manufacturing Technology 54(9-12): 1155-1166

[28] Pathak V K and Singh A 2017 Optimization of morphological process parameters in contactless laser scanning system using modified particle swarm algorithm. Measurement 109: 27-35

[29] Gangwar S, Kukshal V, Patnaik A and Singh T 2012 Computational optimization of $\mathrm{TiO} 2$ filled A384 alloy composites in erosive environment. International Journal of Computational Materials Science and Engineering 1(03): 1250025

[30] Athawale V M and Chakraborty S 2012 Material selection using multi-criteria decision-making methods: a comparative study. Proceedings of the Institution of Mechanical Engineers, Part L: Journal of Materials: Design and Applications 226(4): 266-285

[31] Vahdani B, Zandieh M and Tavakkoli-Moghaddam R 2011 Two novel FMCDM methods for alternative-fuel buses selection. Applied Mathematical Modelling 35(3): 1396-1412

[32] Behzadian M, Otaghsara S K, Yazdani M and Ignatius J (2012). A state-of the-art survey of TOPSIS applications. Expert Systems with Applications 39(17): 13051-13069

[33] Yue Z 2011 A method for group decision-making based on determining weights of decision makers using TOPSIS. Applied Mathematical Modelling 35(4): 1926-1936

[34] Çalışkan H, Kurşuncu B, Kurbanoğlu C and Güven Ş Y 2013 Material selection for the tool holder working under hard milling conditions using different multi criteria decision making methods. Materials \& Design 45: 473-479

[35] Rao R V 2007 Decision making in the manufacturing environment: using graph theory and fuzzy multiple attribute decision making methods. Springer Science \& Business Media 